DOI:

\title{
Return and Volatility Spillover Between Cryptocurrency and Stock Markets: Evidence from Turkey*
}

\section{ABSTRACT}

The aim of the study investigates the return and volatility spillovers and conditional correlations between Borsa Istanbul Stock Exchange 100 Index (BIST100) and Bitcoin (BTC), Ethereum (ETH), Ripple (XRP), and Litecoin (LTH) using daily data for the period between August 07, 2015 and May 20, 2021 with VAR-DCC-GARCH model. We find no bidirectional return spillovers between BIST100 and cryptocurrencies. In line with the volatility spillover results of the study, it has been determined that there is a unidirectional shock transmission from BIST100 to BTC, XRP and LTH, and a unidirectional volatility spillover from BIST100 to BTC and ETH. Also, in the study, it has been determined that the dynamic conditional correlations between BIST100 and four cryptocurrencies have a highly variable over time and their average is very close to zero. However, in possible panic periods, the situation is reversed.

Keywords: Cryptocurrency; BIST; Multivariate GARCH; Volatility Spillover; Return Spillover. JEI Classification: C32, G10, G17.

\section{Kripto Para ve Borsalar Arasında Getiri ve Oynaklık Yayılımı: Türkiye'den Kanttlar ÖZET}

Çalışmanın amacı, 07.08.2015-20.05.2021 tarihleri arasında günlük verileri kullanarak Borsa Istanbul Stock Exchange 100 Index (BIST100) ve Bitcoin (BTC), Ethereum (ETH), Ripple (XRP) ile Litecoin (LTH) arasındaki getiri ve oynaklık dinamikleri ile koşullu korelasyonları VAR-DCC-GARCH modeli ile araştırmaktadır. Çalışmada, BIST100 ile kripto para birimleri arasında her iki yönlü herhangi bir getiri yayllımı tespit edilmemiştir. Çalışmanın oynaklık yayılım sonuçları doğrultusunda, BIST100'den BTC'ye, XRP'ye ve LTH'a doğru tek yönlü şok iletimi olduğu ve BIST100'den BTC'ye ve ETH'a doğru tek yönlü oynaklık aktarımı olduğu tespit edilmiştir. Ayrıca çalışmada, BIST100 ile dört kripto para birimi arasındaki dinamik koşullu korelasyonların zaman içinde oldukça değişken bir yapıda olduğu ve ortalamasının sıfıra oldukça yakın olduğu tespit edilmiştir. Ancak olası panik dönemlerinde durum tersine dönmektedir.

Anahtar Kelimeler: Kripto Para; BIST; Çok Değişkenli GARCH; Oynaklık Yayılımı; Getiri Yayılımı.

JEL Sinıflandırması: C32, G10, G17.

\footnotetext{
* Makale Gönderim Tarihi: 15.11.2021, Makale Kabul Tarihi: 9.12.2021, Makale Türü: Nicel Analiz

** Öğr.Gör.Dr., Hitit University, Vocational School of Social Sciences, ustaogluerkan@hotmail.com, ORCID: 0000-0002-4932-356X.
} 


\section{INTRODUCTION}

The interest of investors, media, academics, and even states in cryptocurrencies continues to grow every day. Since 2008, when Nakamoto (2008) introduced the first cryptocurrency, Bitcoin, to this day, the cryptocurrency market has continued to grow day by day. Today, besides Bitcoin, there are many other cryptocurrencies that have become popular trading assets around the world. The role of cryptocurrency markets has grown rapidly in recent years, attracting considerable attention from academics, the media, government institutions, and the financial industry (Akhtaruzzaman et al., 2020: 1; Guesmi et al., 2019: 431; Klein et al., 2018: 105).The increasing popularity of cryptocurrencies makes them important to explore the dynamics of the cryptocurrency market.

Examining the return and volatility transmission between cryptocurrencies and other assets and exploring the relationship between cryptocurrencies and other assets with different dynamics is crucial for investors. The return and/or volatility transmission between cryptocurrencies and other assets has recently been investigated by several researchers. Conrad et al. (2018) investigated the volatility transmission between Bitcoin and S\&P500 using the GARCH-mixed-data sampling (MIDAS) model. They found that the volatility in the S\&P500 has a negative and significant effect on long-term Bitcoin volatility. Liu and Serletis (2019) and Uzonwanne (2021) extended the study of Conrad et al. (2018). Although Liu and Serletis (2019) and Uzonwanne (2021) conducted similar studies, they reached very different results. Using the vector autoregressive moving average (VARMA)-asymmetric Baba, Engle, Kraft, and Kroner (ABEKK)-GARCH model, Liu and Serletis (2019) examine the volatility spillover between the cryptocurrency market and the S\&P500, DAX30, FTSE100, NIKKEI225 index, and interest rate. The study, the Cryptocurrency Index 30 was used as a representation of the cryptocurrency market. Contrary to the study conducted by Conrad et al. (2018), a long-term negative volatility spillover from the cryptocurrency market to the S\&P500 index was found. Moreover, there is only a short-term positive shock transmission from the cryptocurrency market to the DAX30 index. While there is only a long-term positive volatility transmission from the FTSE100 index to the cryptocurrency market, there is only a short-term positive shock transmission from the NIKKEI225 index to the cryptocurrency market. Also, they highlight that in countries where cryptocurrencies are more accepted and used, the links between markets are stronger. On the other hand Uzonwanne (2021) investigates the return and volatility spillovers between CAC40, NIKKEI225, S\&P500, DAX30, FTSE100, and the Bitcoin market using VARMA- asymmetric GARCH model. The short-term and long-term shock and volatility spillovers between Bitcoin and stock market indices differ significantly at the index level. There is no short-term shock transmission or long-term volatility spillovers between Bitcoin and CAC40. In the long-term, there is a unidirectional negative volatility spillover from the DAX30 and FTSE100 index to the Bitcoin market. While there is a bidirectional negative volatility spillover between NIKKEI225 and BTC in the long-term, there is only unidirectional negative shock transmission from the Nikkei225 index to Bitcoin in the short-term. Finally, although shortterm positive shock transmission and long-term negative volatility spillovers from the S\&P500 index to Bitcoin were detected, only long-term positive volatility spillovers from Bitcoin to the S\&P500 index were detected. When the cross-market return transmission findings of the study are examined, there is a positive return spillover from Bitcoin to the 
S\&P500 index, while a negative return spillover from the FTSE100 to the Bitcoin market. No return transmission has been detected between other markets and Bitcoin. In summary, different results have been obtained that will lead to different strategies for investors. Since the relationship between cryptocurrencies and stock indices vary considerably by period and at the index level, a general interpretation in terms of investment strategies may not be appropriate. Therefore, this topic maintains its currency and obscurity in the literature.

The main purpose of the study is to examine the dynamic conditional correlations and returns and volatility spillovers between Borsa Istanbul Stock Exchange 100 Index (BIST100) and Bitcoin (BTC), Ethereum (ETH), Ripple (XRP), and Litecoin (LTH). The study's second aim of the study is to investigate the hedge ratios and optimal weights of portfolios consisting of BIST100 and cryptocurrency pairs, using the information obtained from the VAR-DCCGARCH model. Our study makes two important contributions to the literature. First, to the best of our knowledge, it is the first study to investigate the dynamic conditional correlations between BIST100 and BTC, ETH, XRP, and LTC, and the interdependence between returns and volatility spillovers. Contrary to the studies in the literature, our study examines the characteristics of four cryptocurrencies.

The main findings of the study can be summarized as follows: Firstly, no bidirectional return spillovers were found between BIST100 and cryptocurrencies. While unidirectional shock transmission was observed between some BIST100/Cryptocurrency pairs, no shock transmission was observed in some pairs. While the lagged volatility of BIST100 increases the volatility of BTC, it reduces the volatility of ETH. Secondly, The average of dynamic correlations between BIST100 and cryptocurrencies is quite close to zero.

\section{DATA}

The dataset of the study includes the daily closing prices of BTC, ETH, XRP, LTC and BIST100 between August 07, 2015 and May 20, 2021. All data are in US dollars. The cryptocurrencies and the BIST100, respectively, were obtained from www.coinmarketcap.com and The Central Bank of the Republic of Turkey database. Returns for the series are calculated as $\ln \left(p_{t_{i} i} / p_{t_{i} i-1}\right)$, where $p_{t_{i} i}$ denotes the price on day $t$.

\section{EMPÍRICAL METHODOLOGY}

\subsection{Multivariate GARCH modeling}

Engle (2002) introduced the DCC-GARCH model against the shortcomings of the multivariate constant conditional correlation-GARCH (CCC-GARCH) model. Unlike other multivariate GARCH models, Engle (2002) DCC-GARCH model allows for the time-varying correlation. Additionally, the number of parameters to be estimated in the DCC-GARCH model increases linearly, not exponentially, thus solving the dimensionality problem in other multivariate GARCH models. The multivariate DCC-GARCH model proposed by Engle (2002) takes place in two stages. In the first step, standardized residues are obtained by estimating GARCH parameters. In the second step, dynamic conditional correlations are obtained using standardized residuals from the GARCH model. 
In our study, following Sadorsky (2012) paper, we use the DCC-GARCH model proposed by Engle (2002) to examine the time-varying correlations in the volatility of BIST100 and cryptocurrency returns. This study uses one lag VAR model to model the return series at the first stage of the DCC-GARCH model. This allows for autocorrelations and cross-autocorrelations in the returns. In the second stage, based on the studies of Chang et al. (2011), Ling and McAleer (2003), and Sadorsky (2012), conditional variance for DCCGARCH models is assumed to be VAR-GARCH(1,1). This allows us to model interdependencies and conditional correlations between BIST 100 and cryptocurrency returns (Chang et al., 2011: 914). The mean equation of the DCC-GARCH model is determined as follows (Sadorsky, 2012: 249):

$$
\begin{aligned}
& r_{t}=\mu+\omega r_{t-1}+\varepsilon_{t} \\
& \varepsilon_{t}=H_{t}^{1 / 2} u_{t}
\end{aligned}
$$

where $r_{t}$ is the vector of returns on the BIST100 stock index and cryptocurrency at time $t, \mu$ is the vector of constant terms, $\omega$ is the matrix of coefficients and $\varepsilon_{t}$ is the vector of the error terms of the conditional mean equation for $r_{t} . u_{t}$ indicates the vector of independently and identically distributed random vector of errors. VAR-GARCH(1, 1) model and the elements of $H_{t}$ is written as:

$$
h_{t}=c+\alpha \varepsilon_{t-1}^{2}+\beta h_{t-1}
$$

where $h_{t}, c, \varepsilon_{t}, \alpha$, and $\beta$ are conditional variance, constant, ARCH coefficients and GARCH coefficients, respectively. The $\alpha$ and $\beta$ respectively, are ARCH coefficients indicating short term persistence and GARCH coefficients indicating long-term persistence. In this study, all models are estimated using the BFGS algorithm and the Quasi-Maximum Likelihood Estimation (QMLE) procedure. Also, a robust estimate of the covariance matrix is used to calculate t statistics.

\section{EMPIRICAL RESULTS}

Descriptive statistics of the returns of the series are given in Table 1. XU100 has the negative average return, while ETH has the highest average return. ETH has the highest volatility, followed by XRP, while XU100 has the lowest. The kurtosis value is relatively high and positive in all return series. This result means that the return series exhibit a leptokurtic distribution. XU100, BTC, and ETH are skewed to the left, XRP and LTC are skewed to the right. The Jarque-Bera test statistic shows that not all series are normally distributed. 
Table 1. Descriptive statistics.

\begin{tabular}{|c|c|c|c|c|c|}
\hline Statistics/Variables & BIST100 & BTC & ETH & XRP & LTH \\
\hline Mean & -0.0003 & 0.0034 & 0.0048 & 0.0034 & 0.0027 \\
\hline Min & -0.1392 & -0.5064 & -1.4362 & -1.2685 & -1.3988 \\
\hline Max & 0.0747 & 0.5269 & 1.2570 & 1.1206 & 1.4309 \\
\hline Std Error & 0.017 & 0.055 & 0.115 & 0.099 & 0.088 \\
\hline Skewness & -1.223 & -0.434 & -1.746 & 0.528 & 0.509 \\
\hline Kurtosis & 7.349 & 20.676 & 61.771 & 40.219 & 96.600 \\
\hline Jarque-Bera & $3614.374^{* * *}$ & $25801.666^{* * *}$ & $230626.190^{* * *}$ & $97525.681^{* * *}$ & $562284.868^{* * *}$ \\
\hline ARCH-LM(20) & $10.025^{* * *}$ & $10.712^{* * *}$ & $32.163^{* * *}$ & $15.978^{* * *}$ & $30.340^{* * *}$ \\
\hline $\mathrm{Q}(30)$ & $45.306^{* *}$ & 31.068 & $68.605^{* * *}$ & $68.684^{* * *}$ & $83.991^{* * *}$ \\
\hline Obs & 1446 & 1446 & 1446 & 1446 & 1446 \\
\hline
\end{tabular}

Notes: ${ }^{* *},{ }^{* *}$ denotes statistical significance at the $5 \%$ and $1 \%$ levels, respectively. $\mathrm{Q}$ and ARCH-LM denotes Ljung-Box Q-statistics, ARCH-Lagrange multiplier test, respectively.

Finally, there is autocorrelation and ARCH effect in all series. Thus, we can investigate the conditional variances and covariances of the return series with the multivariate VAR-DCC-GARCH model.

\subsection{Return and Volatility Spillovers}

Table 2 reports both mean equation and variance equation prediction results of VARDCC-GARCH(1,1) models created with pairs BIST100/Cryptocurrencies. The framework of the mean equation results, $\omega_{11}$ is statistically significant and positive in all four models, indicating that the lagged return of BIST100 positively affects its current return. In other words, the past returns of BIST100 can be used to predict its current returns. Also, there are no autoregressive effects on the current returns of any cryptocurrency. This result, Yousaf et al. (2021) support their findings. In all models, the return spillovers $\left(\omega_{12}, \omega_{21}\right)$ between BIST100 and cryptocurrencies are not statistically significant. So, the past returns of BIST100 cannot be used to predict the current returns of BTC, ETH, XRP, or LTC, and vice versa.

Table 2. Return and Volatility Spillovers for the Pair BIST100/Cryptocurrencies

\begin{tabular}{|c|c|c|c|c|c|c|c|c|c|}
\hline & \multicolumn{2}{|c|}{ BIST100-BTC } & \multicolumn{3}{|c|}{ BIST100-ETH } & \multicolumn{2}{|c|}{ BIST100-XRP } & \multicolumn{2}{|c|}{ BIST100-LTC } \\
\hline & Coeff & T-StatSignif & Coeff & T-Stat & Signif & Coeff & T-Stat Signif & Coeff & T-Stat Signif \\
\hline \multicolumn{10}{|c|}{ Mean } \\
\hline$\mu_{1}$ & 0.000 & 0.5750 .565 & 0.001 & 1.483 & 0.138 & 0.000 & $\begin{array}{lll}0.065 & 0.948\end{array}$ & 0.000 & 0.1690 .866 \\
\hline$\omega_{11}$ & 0.153 & 5.2050 .000 & 0.165 & 6.290 & 0.000 & 0.153 & 4.5520 .000 & 0.160 & 5.1430 .000 \\
\hline$\omega_{12}$ & -0.002 & -0.3390 .735 & -0.001 & -0.083 & 0.934 & 0.002 & 0.4130 .680 & 0.005 & 1.2450 .213 \\
\hline$\mu_{2}$ & 0.004 & 3.4390 .001 & 0.006 & 1.424 & 0.154 & -0.002 & -1.1910 .233 & 0.003 & 1.7420 .081 \\
\hline$w_{21}$ & 0.002 & 0.0300 .976 & -0.098 & -0.778 & 0.437 & 0.092 & 0.7420 .458 & -0.144 & -1.0400 .298 \\
\hline$w_{22}$ & -0.013 & -0.4030 .687 & 0.017 & 0.258 & 0.796 & -0.037 & -0.7950 .427 & 0.027 & 0.6600 .509 \\
\hline \multicolumn{10}{|c|}{ Variance } \\
\hline$c_{1}$ & 0.000 & 2.4750 .013 & 0.000 & 2.377 & 0.017 & 0.000 & 1.8200 .069 & 0.000 & 1.8540 .064 \\
\hline$c_{2}$ & 0.000 & -1.6690 .095 & 0.001 & 2.796 & 0.005 & 0.000 & 2.2630 .024 & 0.002 & 3.6760 .000 \\
\hline$\alpha_{11}$ & 0.144 & 3.2750 .001 & 0.146 & 3.910 & 0.000 & 0.118 & 2.7520 .006 & 0.141 & 2.9470 .003 \\
\hline
\end{tabular}




\begin{tabular}{|c|c|c|c|c|c|c|c|c|c|}
\hline$\alpha_{12}$ & 0.003 & 0.2800 .779 & 0.000 & -0.004 & 0.997 & 0.011 & $\begin{array}{lll}1.232 & 0.218\end{array}$ & 0.001 & 0.1180 .906 \\
\hline$\alpha_{21}$ & -0.368 & -2.9750 .003 & 0.939 & 0.737 & 0.461 & 0.431 & 2.3050 .021 & -1.060 & -4.3670 .000 \\
\hline$\alpha_{22}$ & 0.240 & 3.9920 .000 & 0.157 & 1.463 & 0.144 & 0.257 & $2.400 \quad 0.016$ & 0.824 & 1.5420 .123 \\
\hline$b_{11}$ & 0.652 & 5.4770 .000 & 0.679 & 7.417 & 0.000 & 0.766 & $\begin{array}{ll}7.796 & 0.000\end{array}$ & 0.703 & 5.7930 .000 \\
\hline$b_{12}$ & 0.021 & 0.1540 .877 & 0.011 & 0.311 & 0.756 & -0.015 & -0.7260 .468 & 0.014 & 0.2950 .768 \\
\hline$b_{21}$ & 12.251 & 2.6570 .008 & -3.711 & -2.738 & 0.006 & -0.526 & -0.5050 .614 & 3.672 & 1.2720 .203 \\
\hline$b_{22}$ & 0.606 & 7.0120 .000 & 0.741 & 7.565 & 0.000 & 0.775 & 10.7130 .000 & 0.144 & 1.2850 .199 \\
\hline$\theta_{1}$ & 0.019 & $\begin{array}{lll}1.083 & 0.279\end{array}$ & 0.021 & 0.615 & 0.538 & 0.054 & 1.1640 .244 & 0.061 & 1.9550 .051 \\
\hline$\underline{\theta_{2}}$ & 0.403 & 2.3030 .021 & 0.971 & 22.137 & 0.000 & 0.777 & 4.0930 .000 & 0.679 & 4.9350 .000 \\
\hline Obs & 1445 & & 1445 & & & 1445 & & 1445 & \\
\hline $\log L$ & 6354.129 & & 5399.570 & & & 5731.500 & & 5707.786 & \\
\hline AIC & -8.770 & & -7.449 & & & -7.908 & & -7.875 & \\
\hline SIC & -8.704 & & -7.383 & & & -7.842 & & -7.809 & \\
\hline$Q_{1}(30)$ & 39.144 & 0.123 & 35.905 & & 0.211 & 37.782 & 0.155 & 37.614 & 0.160 \\
\hline$Q_{2}(30)$ & 36.915 & 0.180 & 29.821 & & 0.475 & 22.534 & 0.834 & 37.191 & 0.172 \\
\hline$Q_{1}^{2}(30)$ & 30.504 & 0.440 & 30.585 & & 0.436 & 33.194 & 0.314 & 31.287 & 0.401 \\
\hline$Q_{2}^{2}(30)$ & 11.916 & 0.999 & 10.155 & & 1.000 & 25.535 & 0.699 & 27.122 & 0.617 \\
\hline
\end{tabular}

Notes: $Q(30)$ and $Q^{2}(30)$ indicate Ljung-Box Q-statistics of order 30 for autocorrelation applied to the standardized residuals and squared standardized residuals, respectively.

When the results of variance equation estimation between BIST100 and cryptocurrencies are examined, BIST100's shock spillovers $\left(\alpha_{11}\right)$ and own volatility spillovers $\left(b_{11}\right)$ have a statistically significant and positive effect, indicating that the current volatility of past shocks in BIST100 and also it means that the past volatility in BIST100 increases the current volatility. The own shock spillover of BTC and XRP is significant and positive, indicating that past shocks in BTC and XRP increase current volatility. The volatility spillover of all cryptocurrencies except LTC is significant and positive, indicating that past volatility increases current volatility. The own shock spillover of ETH and both the own shock spillover of LTH and the own volatility spillover of LTH are not statistically significant, which can be interpreted that past shocks of ETH do not affect the short-term current volatility of ETH and past shocks of LTH do not affect the short-term and long-term current volatility of LTH.

When examining volatility spillover effects between markets, no shock transmission effects $\left(\alpha_{12}\right)$ and long-term volatility transmission effects $\left(b_{12}\right)$ were found from cryptocurrencies (BTC, ETH, XRP, LTH) to BIST100. This means that past shocks and past volatility of cryptocurrencies have no effect on the current volatility of BIST100. This finding is similar to the finding of Liu and Serletis (2019) study that there is no long-term volatility transmission from cryptocurrency market to FTSE100 and Nikkei225 index. The transmission effects of shocks from BIST100 to BTC and BIST100 to LTC $\left(\alpha_{21}\right)$ are significant and negative, which means that past shocks in BIST100 reduce the current volatility of BTC and LTC. This result is similar to the findings of Uzonwanne (2021), who found short-term negative shock transmission from Nikkei225 to BTC. The effects of shock transmission from BIST100 to XRP $\left(\alpha_{21}\right)$ are significant and positive, meaning that past shocks in BIST100 increase XRP's current volatility. The long-term $\left(b_{21}\right)$ volatility spillovers from BIST100 to BTC are significant and positive, suggesting that when the lagged volatility of BIST100 increases, the volatility of BTC will also increase. This finding is similar Liu and Serletis (2019) findings that the lagged volatility of the FTSE100 positively affects the volatility of the cryptocurrency market. The long-term $\left(b_{21}\right)$ volatility spillovers from BIST100 to ETH are significant and negative, indicating that ETH's volatility will decrease 
when the lagged volatility of BIST100 increases. In this case, a risk-averse investor should invest in ETH when the volatility of BIST100 increases. Long-term volatility spillovers $\left(b_{12}\right.$, $b_{21}$ ) between BIST100 and XRP and between BIST100 and LTH are statistically insignificant.

The $\theta_{2}$ parameter is positive and significant in all BIST100/Cryptocurrency pairs, while the $\theta_{1}$ parameter is positive in all BIST100/Cryptocurrency pairs, but only BIST100/XRP is significant. The current conditional correlations are due to the effect of past correlations $\left(\theta_{2}\right)$ rather than the effect of past shocks $\left(\theta_{1}\right)$. Also, since the sum of the coefficients is less than one $\left(\theta_{1}+\theta_{2}<1\right)$, this implies that the dynamic conditional correlations tend to revert to the mean.

\subsection{Dynamic Conditional Correlations}

Table 3 and Fig. 1 show dynamic conditional correlations between the BIST100 returns and cryptocurrency (BTC,ETH,XRP,LTH) returns. Although the mean of the dynamic conditional correlations between all pairs in my sample period was positive, it was rather weak. This result, Akhtaruzzaman et al. (2020) support their findings. The dynamic conditional correlation between BIST100 and BTC is generally positive, except for a few periods, and takes the value min -0.171 and max 0.468 during the period. Also, the dynamic conditional correlation between BIST100 and BTC has the highest average value among all other pairs. The dynamic conditional correlation between BIST100 and ETH takes values between -0.227 and 0.520 . A negative correlation was usually observed between BIST100 and ETH until the beginning of 2020, while a positive correlation was observed after this period. Periods when the correlation is negative offer the investor the opportunity to diversify the portfolio. Additionally, the dynamic conditional correlation between BIST100 and ETH has the lowest average among all other pairs. The dynamic conditional correlation between BIST100 and XRP and BIST100 and LTH is highly variable and alternating between positive and negative values. The correlation between BIST100 and XRP range of values between 0.288 and 0.575 , while the correlation between BIST100 and LTH range of values between 0.301 and 0.673 .

Table 3. Summary Statistics of Dynamic Conditional Correlation for BIST100/Cryptocurrency Pairs

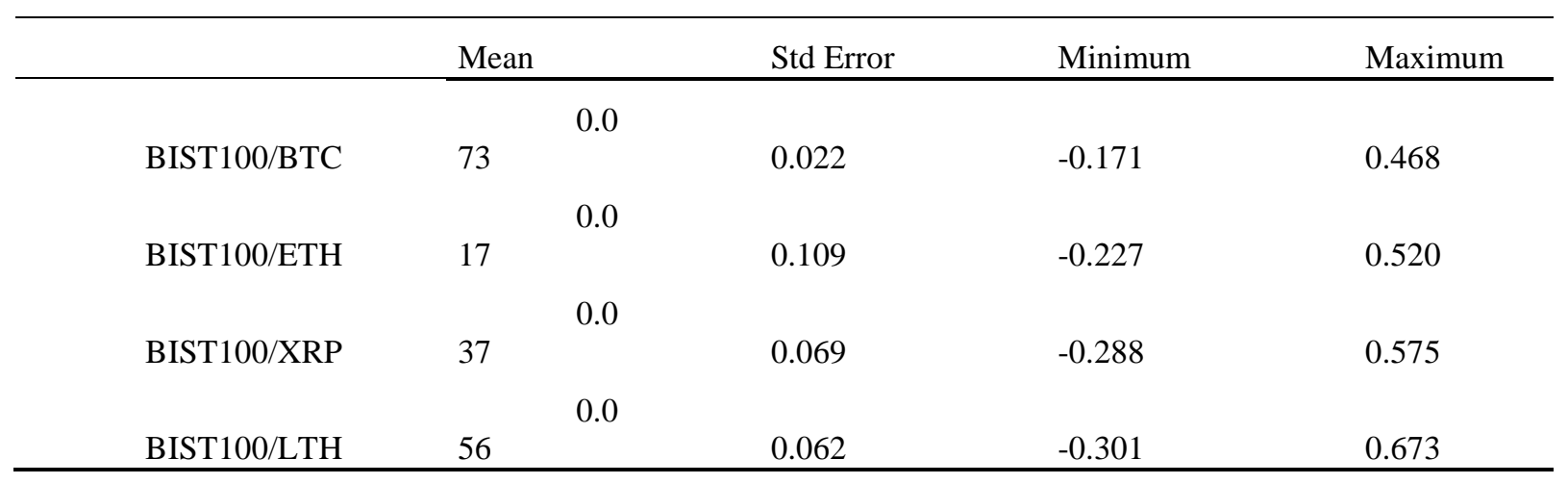



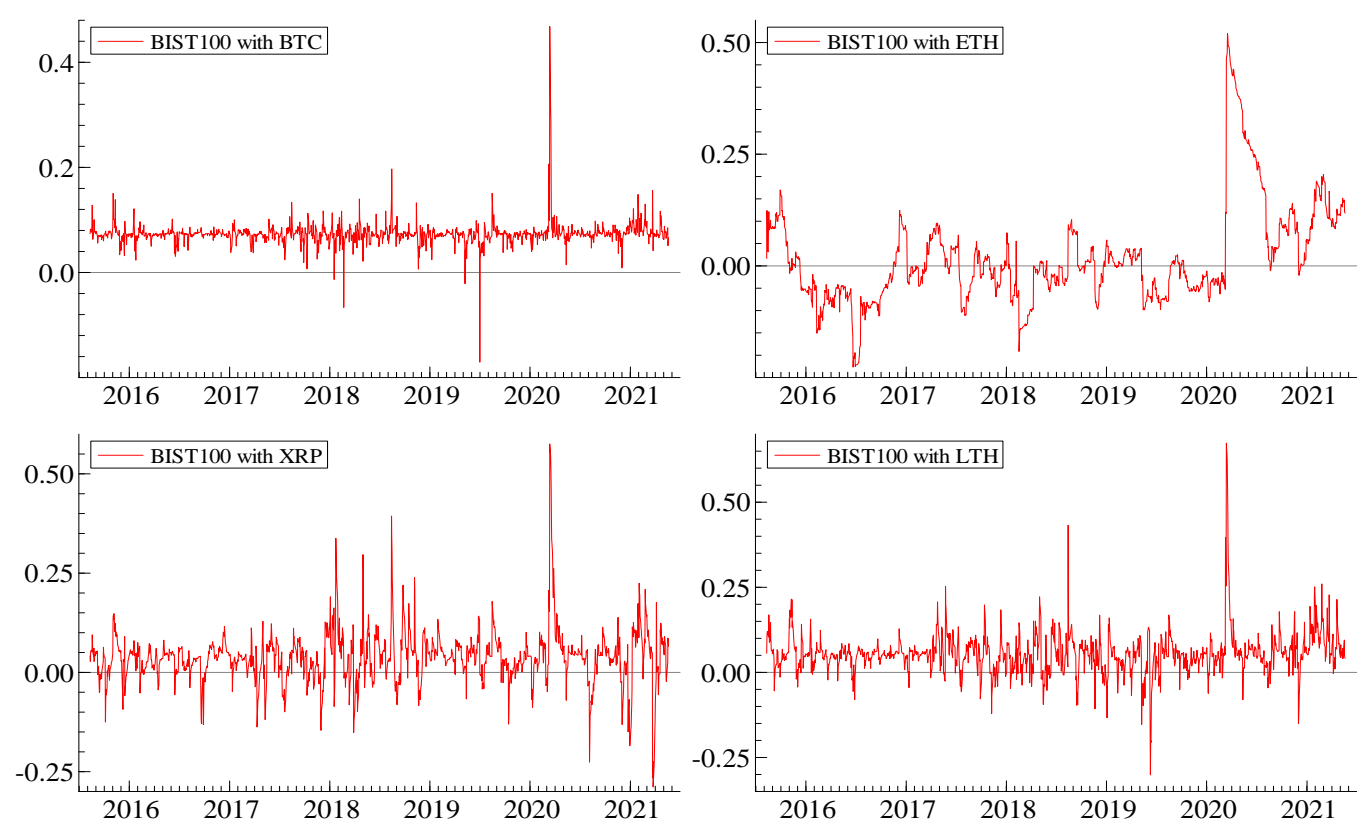

Figure 1. Pairwise Dynamic Conditional Correlations

In all bilateral relations, dynamic conditional correlations peaked in March 2020. More specifically, the correlations between BIST100/BTH, BIST100/XRP, and BIST100/LTH peaked on March 13, 2020, while the correlations between BIST100/ETH peaked on March 17, 2020, two business days later. This result coincides with March 11, 2020, the date of the first Coronavirus case in Turkey, which shows us that portfolios to be created with BIST100 and four cryptocurrencies will not provide diversification benefits during panic periods in the market. This result supports the studies of Charfeddine et al. (2020) and Mariana et al. (2021), who found that the dynamic correlations between cryptocurrencies and the S\&P500 index increased during the Covid-19 period.

In summary, BIST100 and cryptocurrency (BTC,ETH,XRP,LTH) pairs are virtually uncorrelated during the period under review, providing diversification opportunities for investors.

\section{CONCLUSION}

This study examines the dynamic conditional correlations and return and volatility spillovers between BIST100 and BTC, ETH, XRP, and LTC using daily data for the period between August 07, 2015 and May 20, 2020 with the VAR-DCC-GARCH model.

Considering the return spillover findings no bidirectional return spillovers find between BIST100 and cryptocurrencies. This tells us that the historical returns of BIST100 (BTC, ETH, XRP, LTC) cannot be used to predict the current returns of BTC, ETH, XRP, or LTC (BIST100). When the volatility spillovers between BIST100 and cryptocurrencies are analyzed, it is found that there is a unidirectional shock transmission from BIST100 to BTC, BIST100 to XRP, and BIST100 to LTH as well as unidirectional volatility spillovers from 
BIST100 to BTC and BIST100 to ETH. While the lagged volatility of BIST100 increases the volatility of BTC, it reduces the volatility of ETH. Considering these information, a riskaverse investor should invest in ETH rather than BTC, as the volatility of BIST100 has increased.

The average of dynamic correlations between BIST100 and cryptocurrencies is quite close to zero, showing that the assets are almost unrelated to each other and offer diversification opportunities to its investors. However, the situation is reversed during panic phases. For example, the dynamic correlations between all BIST100 and cryptocurrency pairs peaked a few business days after March 11, 2020, the date of the first Coronavirus case in Turkey.

As a result of, investors are advised to keep a close eye on cross-market volatility transfers to avoid cross-market contagion effects. In further studies, it would be interesting to examine the dynamic relationship between cryptocurrencies and Islamic stock market indices over the Covid-19 period and whether cryptocurrencies can be used as a hedging tool against Islamic stock market indices.

\section{REFERENCES}

Akhtaruzzaman, Md - Sensoy, Ahmet - Corbet, Shaen (2020), “The Influence of Bitcoin on Portfolio Diversification and Design”, Finance Research Letters, 37, 101344, pp. 1-8. (https://doi.org/10.1016/j.frl.2019.101344)

Chang, Chia-Lin - McAleer, Michael - Tansuchat, Roengchai (2011), “Crude Oil Hedging Strategies Using Dynamic Multivariate Garch”, Energy Economics, 33(5), pp. 912-923 (https://doi.org/10.1016/j.eneco.2011.01.009)

Charfeddine, Lanouar - Benlagha, Noureddine - Maouchi, Youcef (2020), "Investigating the Dynamic Relationship between Cryptocurrencies and Conventional Assets: Implications for Financial Investors”, Economic Modelling, 85, pp. 198-217 (https://doi.org/10.1016/j.econmod.2019.05.016)

Conrad, Christian - Custovic, Anessa - Ghysels, Eric (2018), “Long-and Short-Term Cryptocurrency Volatility Components: A Garch-Midas Analysis”, Journal of Risk and Financial Management, 11(2), 23( https://doi.org/10.3390/jrfm11020023)

Engle, Robert (2002), “Dynamic Conditional Correlation: A Simple Class of Multivariate Generalized Autoregressive Conditional Heteroskedasticity Models” Journal of Business \& Economic Statistics, 20(3), pp. 339-350 ( https://doi.org/10.1198/073500102288618487)

Guesmi, Khaled - Saadi, Samir - Abid, Ilyes - Zied Ftiti (2019), "Portfolio Diversification with Virtual Currency: Evidence from Bitcoin”, International Review of Financial Analysis, 63, pp. 431-437 ( https://doi.org/10.1016/j.irfa.2018.03.004)

Klein, Tony - Thu, Hien Pham - Walther, Thomas (2018), "Bitcoin Is Not the New Gold-a Comparison of Volatility, Correlation, and Portfolio Performance”, International Review of Financial Analysis, 59, pp. 105-116 ( https://doi.org/10.1016/j.irfa.2018.07.010)

Ling, Shiqing - McAleer, Michael (2003), “Asymptotic Theory for a Vector Arma-Garch Model”, Econometric Theory, 19(2), pp. 280-310 ( https://doi.org/10.1017/S0266466603192092) 
Liu, Jinan - Serletis, Apostolos (2019), "Volatility in the Cryptocurrency Market”, Open Economies Review, 30(4), pp. 779-811 ( https://doi.org/10.1007/s11079-019-09547-5)

Mariana, Christy Dwita - Ekaputra, Irwan Adi - Husodo, Zaäfri Ananto (2021), "Are Bitcoin and Ethereum Safe-Havens for Stocks During the Covid-19 Pandemic?”, Finance Research Letters, 38, 101798, pp.1-7 ( https://doi.org/10.1016/j.frl.2020.101798)

Nakamoto, Satoshi (2008), “Bitcoin: A Peer-to-Peer Electronic Cash System”, Decentralized Business Review , 21260. https://doi.org/10.1.1.221.9986.

Sadorsky, Perry (2012), "Correlations and Volatility Spillovers between Oil Prices and the Stock Prices of Clean Energy and Technology Companies”, Energy Economics, 34(1), pp. 248-255. (https://doi.org/10.1016/j.eneco.2011.03.006)

Uzonwanne, Godfrey (2021), "Volatility and Return Spillovers between Stock Markets and Cryptocurrencies", The Quarterly Review of Economics and Finance, 82, pp. 30-36. (https://doi.org/10.1016/j.qref.2021.06.018)

Yousaf, Imran - Ali, Shoaib - Bouri, Elie - Saeed, Tareq (2021), "Information Transmission and Hedging Effectiveness for the Pairs Crude Oil-Gold and Crude Oil-Bitcoin During the Covid19 Outbreak”, Economic Research-Ekonomska Istraživanja, pp. 1-22. (https://doi.org/10.1080/1331677X.2021.1927787) 